\title{
Demographic Models for Projecting Population \& Migration: Methods for African Historical Analysis
}

\section{Abstract}

This study presents methods for projecting population and migration over time in cases where empirical data are missing or undependable, focusing on a sensitivity analysis to show significance of the modeled parameters. The methods are useful for cases in which the researcher has details of population size and structure for a limited period of time (most obviously, the end point), with scattered evidence on other times. It enables estimation of population size, including its structure in age, sex, and status, either forward or backward in time. The application of these methods developed here is the projection of African populations backwards in time from 1950. The models give particular attention to migration through enslavement, which was highly important in Africa from 1650 to 1900. Details include a sensitivity analysis showing relative significance of input variables and techniques for calibrating various dimensions of the projection with each other. These same methods may be applicable to quite different historical situations, as long as the data conform in structure to those considered here.

Volume 2-3, No. 1 (2014-15) | ISSN 2169-0812 (online)

DOI 10.5195/jwhi.2015.19 | http://jwhi.pitt.edu 


\section{Patrick Manning, Scott Nickleach, Bowen Yi, and Brian McGill}

\section{Demographic Models for Projecting Population \& Migration: Methods for African Historical Analysis}

\section{Population Projection Models in General}

We begin by restating the standard demographic procedures for projecting populations, procedures that can be used for projecting populations either forward or backward over time. In historical analysis, the purpose of the simulation is to carry out a demographically logical projection, with the objective of linking the simulated data with historical data in as many places as possible. The objective, at best, is to develop a detailed picture of population change over time through the consistent interaction of demographic variables, even though the number of corroborative historical observations may be relatively small. The linkage of simulation and scattered empirical data may not yield a unique trajectory of population over the demographic scope and time period analyzed, but it is certain to narrow significantly the historically possible trajectories. ${ }^{1}$ The standard demographic analysis is carried out in five-year periods: variables are measured every five years and population rates are calculated on the basis of the estimated or enumerated populations at the mid-point (or mean) of each five-year period. The most basic distinction in modeling of populations is that between crude rates of demographic change and composition-specific rates.

Crude Rates of Demographic Change. Crude rates of fertility, mortality, migration, net growth, or other types of change may be calculated for an entire population. These are usually calculated as the rates of birth, death, migration, or net increase per thousand persons per year in the original population. Crude rates take almost no account of the details of the population pyramid - the distribution of the population by sex and age.

The crude rate of fertility $\mathrm{F}$ in a five-year period is the number of male and female births $\mathrm{B}(\mathrm{t})$ within that period divided by the mid-point population of males and females, where $t$ refers to full time period and $\mathrm{P}\left(\mathrm{t}^{1} / 2\right)$ refers to the total population midway through the period:

$$
\mathrm{F}=\mathrm{B}(\mathrm{t}) / \mathrm{P}\left(\mathrm{t}^{1} / 2\right)
$$

The crude rate of mortality or deaths $\mathrm{M}$ in a five-year period is the number of deaths $\mathrm{D}(\mathrm{t})$ within the period divided by the mid-point total population in the same period, reported as deaths per thousand persons.

$$
\mathrm{M}=\mathrm{D}(\mathrm{t}) / \mathrm{P}\left(\mathrm{t}^{1} / 2\right)
$$


The crude rate of survival $\mathrm{S}$ is defined simply as $1-\mathrm{M}$ for each mortality rate.

For calculations exclusive of migration, the crude rate of net growth $\mathrm{G}$ of a population in a five-year period is the difference between the total population at the end of the period and at the beginning of the period, divided by the mid-point population, where $\mathrm{t} 0$ and $\mathrm{t} 1$ are the moments at the beginning and end of the period, and where $\mathrm{t}$ is the mid-point time. Assuming there is no migration, the crude rate of net population growth is reported as:

$$
\mathrm{G}=(\mathrm{P}(\mathrm{t} 1)-\mathrm{P}(\mathrm{t} 0)) / \mathrm{P}(\mathrm{t} 1 / 2)=(\mathrm{B}(\mathrm{t})-\mathrm{D}(\mathrm{t})) / \mathrm{P}(\mathrm{t} 1 / 2)
$$

The crude rate of net migration $\mathrm{MI}$ in a five-year period is the number of in-migrants or immigrants $\mathrm{I}(\mathrm{t})$ in that period less the number of out-migrants or emigrants $\mathrm{E}(\mathrm{t})$ in the same period, divided by the midpoint total population in the same period, reported as net out-migrants per thousand persons. (Net out-migration will be negative in cases where out-migrants exceed in-migrants.)

$$
\mathrm{MI}=(\mathrm{I}(\mathrm{t})-\mathrm{E}(\mathrm{t})) / \mathrm{P}(\mathrm{t} \mathrm{t} / 2)
$$

For calculations accounting for migration, the crude rate of net growth $\mathrm{G}$ may be written as the sum of the crude rates of birth, death, and migration (which again is positive where in-migrants exceed out migrants).

$$
\mathrm{G}=\mathrm{B}-\mathrm{M}+\mathrm{MI}
$$

Changes in status within a population may be expressed in terms of crude rates in a fashion analogous to the handling of migration. Changes in status may be defined as migrations from one subgroup of a population to another-for instance, from children to adults, from free to slave, from non-smoker to smoker. A further extension of this logic is to argue that various economic, social, or environmental influences may influence rates of mortality or rates of net population growth, either positively or negatively. The various environmental influences on the crude growth rate may be summed to give the crude rate of net growth, where G1 $\ldots$ G4 are the growth rates due to various environmental influences:

$$
\mathrm{G}=\mathrm{G} 1+\mathrm{G} 2+\mathrm{G} 3+\mathrm{G} 4
$$

Crude-rate calculations have the benefit of ease of calculation and straightforward comparability from population to population. It is possible to identify and sum rates of change for many different factors, including those that are not demographic at base, such as famine or flood. On the other hand, crude rates are not sensitive to shifts in the age or sex composition of the population.

Composition-specific Rates of Demographic Change in Closed Populations. Composition-specific demographic rates are calculated most basically with regard to age and sex. That is, the demographic variables of fertility and mortality may be broken down in composition by age, sex, and status. For an individual population, the standard composition-specific model approximates a continuous process, like most such models, and is expressed in terms of five-year age groups. ${ }^{2}$ All the populations exist at each moment; they change in size and structure in response to their various rates of fertility and mortality. The populations are the variables in the analysis; the rates of fertility and mortality are taken as parameters. The analysis consists of determining which parameters are most important, both theoretically and historically, in setting patterns of population change.

The standard projection for a closed population is based on an analysis of five-year age groups from 0-4 to 80+, five-year periods, and a single-sex model of reproduction. Projections are usually done in terms of survival rather than mortality: thus, survival in each age group above birth is calculated as the age-specific survivorship rate multiplied by the previous population. For the youngest and oldest cohorts among these age groups, calculations 
must be performed slightly differently. For the youngest cohort, female births in the population are calculated as the age specific annual fertility rate multiplied by the mid-period population, then by five years of exposure, and summed over all childbearing years (usually assumed to be from ages 15 to 49). Then survivorship among those females born in the current period is calculated as the number of female births multiplied by the female birth survival rate; these surviving births then survive the remainder of the period at the $0-4$ survival rate. Male births in each population are calculated as a constant proportion of female births (usually 1.03); survivorship of male babies is determined by the male birth survival rate. For the oldest cohort in the population (taken here as ages $80+$ ) the survivors in that group are taken to be T80/T75, where T80 and T75 are the number person-years lived in the population up to ages 80 and 75 , respectively. ${ }^{3}$

The projected population in each period can yield crude rates of birth and mortality. The crude birth rate is then the sum of all surviving male and female births in each five-year period divided by the midpoint population of all age groups totaled. The crude death rate is the sum of all deaths divided by the midpoint population. The crude rate of natural increase is the sum of the birth and death rates. The data required in order to complete the projection of a single closed population include an initial population of appropriate age-sex structure, a schedule of mortality rates, and a schedule of fertility. ${ }^{4}$

Inclusion of Migration. To account for migration in population projection, it is necessary to model multiple populations. Each population linked by migration may have varying rates of birth, mortality, and migration, where each of these rates must be identified in age-specific and sex-specific terms. Further, schedules of out-migration rates and in-migration rates must indicate not only the proportions that migrate but also the proportions following various paths in migration": this can be labeled as a "partition schedule" for migrants. The populations are linked to each other by inflows and outflows of migrants, directed from population to population. The "migration" may include physical movement of migrants from place to place, but it may also include changes in status within a single population or in moving from one population to another.

Migration could be assumed to be instantaneous, in which case the migrants are either in their home population or destination population. But since migration has often been a time-consuming process, involving significant mortality, there is an argument for adding this factor explicitly into the model. This approach is implemented by assuming that, on becoming migrants, individuals leave their home population and enter a separate "migrant" population: they remain in this migrant population for one or two years until they leave it and migrate into their destination population. In this case, the migrant populations must be attributed with rates of birth and mortality as well as with a specific trajectory of migration. For long, physical migrations, because of exposure to unfamiliar elements, it may be expected that migrant mortality rates are higher and that their fertility rates are lower than in their home populations. On the other hand, migrations across boundaries of status within the home population may not impose differences in fertility or mortality. Status can be broken down into additional subcategories by ethnicity, religion, or occupation. With regard to slave status one may distinguish persons who are free, captive, slave, liberated, or slave-descended.

With migration, the number of data files required for population projection increases. The initial single population now becomes several populations: home populations from which migrants depart, destination populations in which migrants settle, and populations of migrants on the move (existing for the time from departure from home population until settlement at the destination.) Rates of mortality and fertility for these populations may be at different levels. In addition, a migration schedule determines the number of migrants (by age and sex) for each 
population in each population; and a partition schedule determines the direction of each migrant toward an intended population of settlement. ${ }^{6}$

\section{Population Projections before 1890 with African data}

The framework that we have adopted for analysis of African population spans the period from 1650 to 1950 and the whole of the African continent, allocated among 66 regions that are based on modern national and provincial boundaries. The regional boundaries, kept consistent for the whole time period, also take substantial account of African ecological regions and the social regions marked by the flows of slave trade.

Analysis is conducted in two long periods, divided at 1890, and in sub-periods and sub-regions for the earlier period. First, analysis for the years after 1890 - the colonial era-is conducted through crude-rate analysis. For this colonial era, migration is assumed to be relatively small in volume, while vital rates of birth, death, and other factors are assumed to be variable. The crude-rate approach is most appropriate here, in that it allows for inclusion of numerous factors and shifts in parameters. ${ }^{7}$ Second, analysis for the years before 1890 is conducted through composition-specific techniques, focusing especially on the movement of migrant captives: this is the principal focus of the present article.

Composition-specific simulation. This simulation is an electronic implementation of the composition-specific model described above. ${ }^{8}$ The composition-specific approach is most appropriate here, as it allows for detailed investigation of the effects of shifts in age and sex composition in response to migration. The simulation is a digital model written in the R language, in which such events as birth, death, and enslavement take place continuously but are measured within periods of five years. Composition-specific model accounts for relations among multiple populations. The populations are labeled as the "Source" population (from which migrants are taken), the "Captor" population (which avoids losing migrants), the "Domestic Slave" population in Africa, and the "Export Slave" population outside of Africa. The migrant populations are the "Captives" (those taken from the Source population by enslavement), the "New Domestics" (those Captives who are added into the Domestic Slave population after their travels), the "New Africa Exports" (those captives embarked on ships or caravans leaving sub-Saharan Africa), and the "New Exports Abroad" (those disembarked from ships or caravans who are added into the Export Slave population after their travels). ${ }^{9}$ The size and structure of the Source and Captor populations are given as initial conditions. Source and Captor populations in subsequent periods and all other populations and numbers of migrants are variables that are calculated in the simulation. The parameters for these calculations are the various assumed demographic rates: rates of survival for each population, rates of fertility for each population, and rates of migration - which result from schedules of capture and partition. That is, the capture schedule gives the proportion of Captives taken from the Source population, by age and sex, in each five-year period; the Partition schedule determines the proportion of Captives, by age and sex, who are directed to become Domestic Slaves or Export Slaves. Seventeen input data files must be entered into the continental simulation. Actual data files used in the simulation, along with description of their characteristics, are available on a website providing details on the African continental simulation. ${ }^{10}$

To address the empirical specifics, the initial populations are the Captor and Source populations, each with a life expectation at birth of 22.5 years and a growth rate of $0.2 \%$ per year. Enslavement takes place each year, and an average one percent of the Source population is captured. This raid or other process of enslavement creates, in each period, a Captive population. The Captive population suffers a severe initial mortality, including those losing their lives in the course of capture and those dying as a result of disease and exposure while in captivity. The Captives 
then undergo a "partition," in which some Captives are retained in Africa while others are destined for sale outside the continent. Those retained in Africa, the New Domestics, suffer a severe initial mortality, including those losing their lives in the course of capture and those dying as a result of disease and exposure while in captivity; the survivors are added to the population of Domestic slaves. Those destined for export, the New Africa Exports, undergo a similar mortality in the course of their journey to the African frontier. They then suffer another severe mortality, averaging about 15\% and corresponding to the Middle Passage; the survivors become New Exports Abroad who join the Export slave populations of the New World diaspora or the Old World diaspora.

One important further point is that, with migration, it is necessary to run the simulation for multiple periods in order to give an approximation of a continuing impact of enslavement-induced migration, rather than simply isolated five-year periods. An overall practice of 40 -year simulations was adopted. That is, one must simulate the impact of enslavement on the assumption that it has been going on for some time (in practice, some 40 years), rather than assume that enslavement has just begun. ${ }^{11}$

This composition-specific simulation program is implemented in two versions: the export-driven version, in which African slave exports are large in quantity and drive the overall process of enslavement in Africa, and the continental-enslavement version, in which enslavement arises primarily from demand for slaves within the African continent and slave exports are small in quantity. In both versions, migration is assumed to be significant and influential, while changes in vital rates and other factors are assumed to be small. In practice, the two versions can be alternated and mixed to match the changing historical situations, as will be shown in the concluding section of this study.

The Export-driven version. In this version it is assumed that capture, sustained especially by the demand for export slaves, results in capture of a cross-section of Source populations. Roughly half of the captives are become New Africa Exports, though the sexual composition of the New Africa Exports differed by region of the African coast or Sahara fringe. Atlantic Africa (the coasts of West Africa and Central Africa) exported mostly males, by a ratio of almost 2:1. In contrast, the captives exported across the Sahara and the Indian Ocean were dominantly female, in a ratio of about $0.7: 1$ or $0.8: 1$ males per female. As a result of the disproportionate export of male captives (across the Atlantic) and female slaves (across the Sahara and Indian Ocean), the adult sex ratio of African populations also shifted, such that the adult population was predominantly female in West and Central Africa but dominantly male in eastern Africa and along the Sahara fringe.

The Continental-enslavement version. In this version of the simulation, it is assumed that enslavement takes place, but that no persons are exported from African in slavery. The model for population projection is in most respects the same. ${ }^{12}$ That is, the Source population loses people to capture each period. These captives undergo a partition according to their expected destination within Africa, and then undergo a severe mortality as New Domestics; the survivors are incorporated into the Domestic slave population. The potential complexity of this version of the model is in the geographic destination of the New Domestics (the simulation model divides the African continent into 64 regions). The calculation is simple if it is assumed that New Domestics remain in the region of their capture. Calculations become more complex if it is assumed, more realistically, that many New Domestics were transported and sold to other African regions, where it would be more difficult for them to escape.

Relying on the basic model and its variants as described here, the simulation program calculates populations, by decade and by region, for African regional populations, for slaves held within sub-Saharan Africa, for slaves and 
slave-descended populations in the diaspora - the Americas, North Africa, and the Indian Ocean—and for captives moving among these destinations.

In addition to these population sizes and migrant flows, the simulation calculates rates of birth, death, migration, growth, and other parameters. In particular it calculates one calibrating variable and two major dependent variables, all of which are important both in calibrating the simulation (so that its results are not far distant from those known from the historical record, and in providing interpretive statements on the impact of slave trade on African and diaspora population. These variables, in turn are central to the sensitivity analysis of the interaction of variables and parameters in the analysis, to which we now turn.

\section{Estimating sensitivity for Atlantic projections, $16^{\text {th }}-18^{\text {th }}$ centuries}

Since the simulation uses seventeen data files on population, fertility, mortality, and migration, questions immediately arise as to the sensitivity of output to changes in input, and as to interactions among the various files of input data. This section summarizes the results of a sensitivity analysis of interaction effects among input variables. The sensitivity analysis depends on the specific variables and parameters selected for analysis of the Atlantic slave trade in the eighteenth century. ${ }^{13}$

The sensitivity analysis could be conducted with any of the versions in modeling slave trade listed above. We have chosen to do the calculations for the export-driven version of the simulation program, focusing on the Atlantic slave trade before 1790, and we argue that the results of this analysis can be extended, in large degree, to the other variants. The sensitivity test begins with our historical window on the issue: the size and composition of the New Africa Exports population, corresponding to the levels of captive exports (by region and by decade). To link this population to the structure of the population remaining in Africa, we must define our output calibration variable (E or EXPRATIO) as the ratio of the flow of New Africa Exports to the stock of the African Regional population. The African Regional population is given in the initial conditions for each stage of the simulation. The sensitivity analysis, then, is a study of the relationship of dependent or output variables with independent or input variables and parameters. ${ }^{14}$

The independent input variables, classified here into a group of twelve, are assigned variables that lead them to change in five increments by from $10 \%$ to $40 \%$.

Independent Variables:

1 Source/Captor Population Survival Rates ${ }^{15}$

2 Migration Survival Rates

3 Domestic/Export Slave Survival Rates

4 Source/Captor Population Fertility Rates

$5 \quad$ Migration Fertility Rates

$6 \quad$ Domestic/Export Slave Fertility Rates

7 Amount of Capture via capture array

8 Sex Composition implied by capture array

$9 \quad$ Age Composition implied by capture array

10 Amount of Retention via partition array

11 Export Sex Composition implied by partition array

12 Export Age Composition implied by partition array 
We use five different levels for each of the independent variables, which are generated by modifying the default arrays as follows:

\begin{tabular}{|c|c|c|}
\hline Variable & Levels & Modifications to Default Arrays to Obtain Levels \\
\hline 1 & $1,2,3,4,5$ & Multiply Source/Captor Survival by .96, .98, 1, 1.02, and 1.04 \\
\hline 2 & $1,2,3,4,5$ & Multiply Migration Survival by .96, .98, 1, 1.02, and 1.04 \\
\hline 3 & $1,2,3,4,5$ & Multiply Domestic/Export Survival by .96, .98, 1, 1.02, and 1.04 \\
\hline 4 & $1,2,3,4,5$ & Multiply Source/Captor Fertility by .96, .98, 1, 1.02, and 1.04 \\
\hline 5 & $1,2,3,4,5$ & Multiply Migration Fertility by $.96, .98,1,1.02$, and 1.04 \\
\hline 6 & $1,2,3,4,5$ & Multiply Domestic/Export Fertility by .96, .98, 1, 1.02, and 1.04 \\
\hline 7 & $1,2,3,4,5$ & Multiply Capture Array by .8, .9, 1, 1.1, and 1.2 \\
\hline 8 & $1,2,3,4,5$ & Multiply women\men in Capture Array by $1.25 \backslash .75,1.1 \backslash .9,1 \backslash 1, .9 \backslash 1.1$, and $.75 \backslash 1.25$ \\
\hline 9 & $1,2,3,4,5$ & 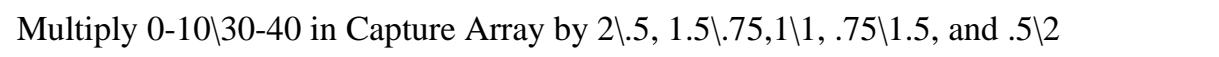 \\
\hline 10 & $1,2,3,4,5$ & Multiply Partition Array by $.96, .98,1,1.02$, and 1.04 \\
\hline 11 & $1,2,3,4,5$ & Multiply women\men in Partition Array by $1.1 \backslash .9,1.05 \backslash .95,1 \backslash 1, .95 \backslash 1.05$, and $.9 \backslash 1.1$ \\
\hline 12 & $1,2,3,4,5$ & 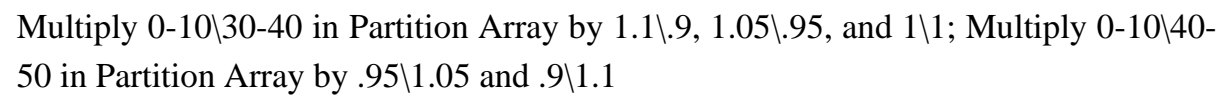 \\
\hline
\end{tabular}

Table 1. Modifications to Default Arrays

We attempted to achieve equal spacing of the levels 1-5 in the way we modified the default arrays, e.g. in equal increments of $2 \%$ in survival and fertility rates. Furthermore, we attempted to modify capture and partition arrays to generate variables 7-9 and 10-12 in such a way that modifying the array has an impact only on the actual levels of the desired variable. For example, default source population and capture rates are both roughly equal across gender, so that multiplying the array by .8, .9, 1, 1.1, and 1.2 to obtain the levels of capture size for variable 7 will not have a great impact on the levels of the capture sex ratio in variable 8 or capture age ratio in variable 9. Modifications also had to be constructed so as not to violate logical bounds. For example, multiplicative adjustments to the partition array cannot result in a partition rate greater than 1 for any combination of age and gender.

Three dependent variables are defined as an output calibration variable and two output prediction variables. The output calibration variable is E or EXPRATIO, the ratio of the Africa Exports population to the African Regional Population. Simulation input data are adjusted to ensure that EXPRATIO remains within estimated historical limits. The output prediction variables are G or GROWTH RATE (the annual growth rate of the African Regional Population) and S or SEXRATIO (the ratio of men to women of marriageable age in African Slave Society). The latter two variables are not directly observable from historical data, while approximations of EXPRATIO may be constructed using empirical data on slave exports and estimated African populations. The 
research design, therefore, is to seek out correlations among the determinants of all three output variables, so that we may use documented levels of $\mathrm{E}$ to project estimated levels of $\mathrm{G}$ and $\mathrm{S}$. This requires equivalent sensitivity analyses for the two output prediction variables.

We use the sample function in the S+ language to randomly generate a collection of levels for each of the 12 independent variables. After making the corresponding modifications to the default arrays, we run the simulation program for 40 years, and record each of three dependent variables. We repeat this procedure to obtain many different combinations of levels of independent variables and the corresponding values of dependent variables. Before attempting to quantify the relationship between the dependent and independent variables, we impose admissibility criteria as follows, deleting estimates that fail to meet these standards:

1 Proportion of exports who are female must be between .3 and .4

2 Proportion of exports between ages 0 and 20 must be between .2 and .3

3 Export ratio must be between .002 and .01

Any combination of independent variables that yields output failing to satisfy all three criteria is discarded as inadmissible. We then take the remaining collection of admissible combinations of independent and dependent variables and regress each of the dependent variables on the independent variables. We take as our measure of the sensitivity of a dependent variable to a given independent variable the amount of variation in the dependent variable explained by that independent variable.

DEPENDENT VARIABLE: EXPORT RATIO $\quad \mathbf{R}^{2} \quad$ sum $\mathbf{R}^{2}$

\begin{tabular}{|l|c|}
\hline Source/Captor Survival Rates & .0002 \\
\hline Migrant Survival Rates & .0138 \\
\hline Domestic/Export Survival Rates & .015 \\
\hline \hline Source/Captor Fertility Rates & .0001 \\
\hline Migrant Fertility Rates & .0024 \\
\hline Domestic/Export Fertility Rates & .0025 \\
\hline \hline Amount of Capture via capture array & .2599 \\
\hline Sex Composition implied by capture array & .0279 \\
\hline Age Composition implied by capture array & .04350 \\
\hline \hline Amount of Retention via partition array & .6349 \\
\hline Export Sex Composition implied by partition array & .0000 \\
\hline Export Age Composition implied by partition array & .0001 \\
\hline \hline TOTAL & .9562 \\
\hline
\end{tabular}

Table 2. Sensitivity Analysis: Dependent Variable EXPRATIO 
Results of the sensitivity analysis on the EXPRATIO variable are shown in Table 2. Results, reported in the

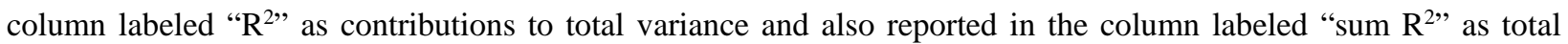
variance for each group of three variables (survival, fertility, etc.). These results indicate the relative importance of input variables in causing variation in the output variable, EXPRATIO.

The results of this analysis indicate that the main determinants of EXPRATIO are the sex composition of capture and the nature of the partition of captives into domestic and exported slaves. Other measurable effects are provided by the size of the raid, the survival rates of captives and the survival rates of the general African population. These independent variables on the age-sex composition of capture and partition-while by no means the best documented in the history of African enslavement—are thus shown to be the ones on which researchers should focus the most energy on learning more.

Table 3 shows the sensitivity analysis results for GROWTH (African growth rates), under the impact of slave exports, correlate primarily with mortality rates of African populations and only secondarily with such slave-trade variables as the size, sex, and age composition of capture.

DEPENDENT VARIABLE: GROWTH RATE $\mathbf{R}^{2} \quad$ SUm $\mathbf{R}^{2}$

\begin{tabular}{|c|c|}
\hline Source/Captor Survival Rates & .9355 \\
\hline Migrant Survival Rates & .0012 \\
\hline Domestic/Export Survival Rates & .0001 \\
\hline Source/Captor Fertility Rates & .0126 \\
\hline Migrant Fertility Rates & .0015 \\
\hline Domestic/Export Fertility Rates & .0002 \\
\hline Amount of Capture via capture array & .0175 \\
\hline Sex Composition implied by capture array & .0184 \\
\hline Age Composition implied by capture array & .0017 \\
\hline Amount of Retention via partition array & .0131 \\
\hline Export Sex Composition implied by partition array & .0026 \\
\hline Export Age Composition implied by partition array & .0000 \\
\hline TOTAL & .9974 \\
\hline
\end{tabular}

Table 3. Sensitivity Analysis: Dependent Variable GROWTH

This result shows that the demographic character of slave trade itself did not determine the rate of African population growth, since levels of African mortality did more than anything else to determine patterns of African population growth and decline. Nonetheless, these sensitivity results enable us to argue that net African growth rates 
were negative in the slave-trade era unless mortality, combined with high African birth rates, was low enough to permit an intrinsic African growth rate that was greater than one percent per year.

For the sex ratio in Africa, on the other hand, we find that the main correlates of SEXRATIO are relatively close in proportion to the determinants of EXPRATIO (partition, capture, fertility, and survival).

DEPENDENT VARIABLE: SEX RATIO $\quad \mathbf{R}^{2} \quad$ sum $\mathbf{R}^{2}$

\begin{tabular}{|c|c|}
\hline Source/Captor Survival Rates & .0000 \\
\hline Migrant Survival Rates & .0004 \\
\hline Domestic/Export Survival Rates & .0001 \\
\hline Source/Captor Fertility Rates & .0017 \\
\hline Migrant Fertility Rates & .0000 \\
\hline Domestic/Export Fertility Rates & .0006 \\
\hline Amount of Capture via capture array & .0001 \\
\hline Sex Composition implied by capture array & .0781 \\
\hline Age Composition implied by capture array & .0016 \\
\hline Amount of Retention via partition array & .0080 \\
\hline Export Sex Composition implied by partition array & .8506 \\
\hline Export Age Composition implied by partition array & .0011 \\
\hline TOTAL & .9423 \\
\hline
\end{tabular}

Table 4. Sensitivity Analysis: Dependent Variable SEXRATIO

These are the variables defining the size and composition of enslavement and of the partition between domestic and exported slaves - and in almost the same relative importance for SEXRATIO and EXPRATIO. We may thus hope to predict confidently the adult sex ratios of African populations from what we know about the composition of the New Africa Exports slave populations.

This sensitivity analysis enables us to check the logic and consistency of the assumptions in the simulation by combining results of these three tables. For example, if we could decrease the proportion of women captured and also increase the proportion of women exported, we could recalibrate EXPRATIO and project a more equal African sex ratio and greater African growth rate. But the evidence against making such a change in assumptions includes the consistent excess of female slave prices over male slave prices in African slave markets and the qualitative accounts attesting to the large number of female slaves in Africa. More generally, this sensitivity analysis confirms, at a higher level of statistical sophistication, an earlier sensitivity analysis on simulation of African slave trade, published in 1988. That simulation and the accompanying sensitivity analysis, constructed in a somewhat different fashion, nevertheless gave substantially similar results. ${ }^{16}$ 


\section{Model Calibration and "Autonomous" Enslavement}

For the whole period of export slave trade, the Atlantic slave trade exported primarily male captives, leaving West and Central Africa with a relative shortage of males, while the Saharan/Indian Ocean slave trade exported mostly females, leaving Northeast and East Africa with a relative shortage of females. Starting with this distinction, we end up calculating African populations of various times and places according to varying procedures. For the period from 1650 to 1790, for both the Atlantic and Saharan/Indian Ocean slave trades, we assume that the level of retention of enslaved persons on the African continent was a relatively stable "by-product" of export slave trade. The exported captives in this period, as noted above, were dominantly male for the Atlantic slave trade from West and Central Africa, and dominantly female for the Indian Ocean and trans-Saharan slave trade. We assume that domestic enslavement expanded along with the export slave trade as it grew up to the end of the eighteenth century (and, for eastern Africa, for much of the nineteenth century.) For Africa in the period from 1790 to 1890, in contrast, we assume that the capture and retention of enslaved persons on the African continent was sometimes a "byproduct" but more often "autonomous" - that is, enslavement was able to expand even when the level of slave exports declined. As a result, the nineteenth century was clearly the peak era of enslavement for Africa as a whole.

To complete the overall procedure of estimating African populations and migration from 1650 to 1890, we need to address three remaining problems: (1) linking and calibrating the modeled exports with empirical estimates of slave exports; (2) estimating levels of continental African enslavement as a by-product of export slave trade, especially for the period up to 1790 but also as long as export slave trade continued; and (3) estimating the nineteenth-century levels of continental enslavement, captive mortality, and slave populations that were autonomous from export slave trade.

Calibrating Simulations with Empirical Data. The several types of demographic information associated with this project need to be linked to one another-through to calibration that renders the various types of calculations consistent with one another, ultimately yielding a coherent vision of the demographic system of Africa and the African Diaspora. The various sets of data are simulations of continental African population, estimations of the flows of captives from Africa to other regions, and censuses or other estimates of populations in regions of the African diaspora. Data on out-migration are identified empirically or drawn from output of the model. These outmigrations then yield data on in-migration for external regions - the Americas, North Africa, and the Indian Ocean world.

For all of the versions of the continental projection, it is necessary to calibrate the simulation output with reference to historical data on the size and structure of the external slave trade. That is, the simulation yields projections not only for the continental population but also the number of captives exported from each region for each period. Empirical data on the slave trade, when compared to simulation projections, can indicate that changes in input files are necessary to yield a stream of slave exports of the appropriate size and structure.

For the Sahara and Indian Ocean, empirical estimates of slave exports consist of aggregate figures compiled by authorities, summarized as exports per year or per decade from specified regions. Simulated regional populations, combined with assumed rates of capture and partition, produce simulated rates of captive export by region and decade. Calibration consists of comparing the simulated exports with the empirical estimates. To resolve any discrepancies, revisions are made in the assumed rates of capture, partition, and perhaps other demographic parameters. Once the input is revised, the simulation is run again until the output fits that of the empirical estimates. The resulting figures for population and migration are thus taken as the best current estimates for population of the northern and eastern regions of Africa. 
For West and Central Africa, empirical estimates of slave exports are based on the online dataset, Slave Voyages, a compilation of researchers of many scholars led by David Eltis. ${ }^{17}$ The dataset, while remarkably complete, is still missing many entire voyages and is missing much data on the voyages included. In analysis to be reported separately, we used techniques of Markov Chain Monte Carlo to estimate the missing values and the total numbers of slaves exported by region and decade. In addition information from the Slave Voyages dataset make it possible to estimate the ratio of male to female captives shipped from African regions in each decade. These empirical estimates of slave exports are then compared with the simulated response. To resolve any discrepancies, revisions are made in the assumed rates of capture, partition, and perhaps other demographic parameters.

Continental enslavement as a "by-product" of export slave trade: 1650 to c. 1790. The simulation is written so as to allow any proportion of captives to be sold abroad. In fact, the parameters selected for the analysis have assumed that roughly half of the captives were sent abroad, and the other half retained. More precisely, the assumption is that capture gathers a cross-section of the population, though with a slightly higher proportion of young adults. In the Atlantic, export demand and prices were higher for male captives, with the result that the ratio of exports was roughly 2:1, male:female. Therefore, for those retained in slavery within Africa, the ratio was roughly 1:2, male:female. For slave trade across the Sahara and the Indian Ocean, the levels of demand and price were roughly inverted: exports were roughly 1:2, male:female, while for those retained in slavery within Africa the ratio was roughly 2:1, male:female.

Of course local conditions varied greatly over time and space, but we emphasize that, before the nineteenth century, demand for slave exports was primary, and that continental enslavement was a "by-product" of overseas slave trade - roughly equal in volume but inverse in its sexual composition. The accompanying historical argument is that the growing external demand was what caused African enslavement to increase, and that the level of enslavement in Africa grew in rough parallel to the level of captive exports overseas. We assume that this was the case throughout Africa up to 1790 .

Continental enslavement as "autonomous," 1790 - 1890. It has long been known that the volume and the geographical extent of enslavement expanded during the nineteenth century. ${ }^{18}$ Aside from some very general, continent-wide estimates made decades ago, there have been no attempts to address explicitly the volume of enslavement during the nineteenth century. ${ }^{19}$ The temporal peak in export slave trade varied by region-as early as 1790 in parts of West Africa and as late as 1870 in parts of East Africa. More generally, however, enslavement within the continent continued at a high and sometimes expanding level after the decline in overseas slave exports. Qualitative descriptions of this expanded enslavement are common but scattered, and it has not been obvious how to sum up the overall pattern. To begin a process of estimation, our group has developed additional models. First, the level of enslavement is simply set arbitrarily, and captives are assumed to be held in slavery within their home territory. Second, as a further device for exploring nineteenth-century enslavement, an additional model was developed for heuristic purposes: in this case, for the nineteenth century, the "by-product" model was utilized up to the decade with the maximum number of slave exports. For decades thereafter, the level of enslavement was maintained at the same level through the 1880s, then dropped to near zero. This had the advantage of calculating the volume of continental enslavement through a functional relationship related in part to export slave trade. In practice, however, this approach does not seem to have fit closely to available empirical data.

Third, we found that, for our purposes, the modeling of African enslavement in the nineteenth century is best accomplished with a mix of the export-driven and continental-enslavement models, as shown in the concluding section of this study. That is, we combine the steps of increasing the capture schedule and then adjusting the 
partition schedule so that steadily greater portions of captives are maintained within the continent. This is the equivalent of mixing proportions of the simulation models described above as export-driven and continentalenslavement models. This approach makes it possible to assume that the level of enslavement expanded indefinitely, and to observe the simulated results for continental populations.

The practical implementation of this revision of the simulation model is not difficult-it is carried out through simple adjustment of input files for capture and partition. The question of how far continental captives traveled before their settlement as slaves is unanswered empirically, though there is a simple solution in computation. ${ }^{20}$ Beyond these issues in calculation, two contradictory interpretive problems arise. First, there appear to be no demographic relationships by which to estimate the historical level of enslavement. That is, the proportion of African populations enslaved in each region and period appears to be "autonomous"-indeterminate and arbitraryin that there is no clear way to calibrate it with other information in the system.

Nonetheless, in contrast, if one looks broadly enough there does seem to be a general pattern in nineteenthcentury enslavement. The qualitative historical record for tropical Africa and Asia in the nineteenth century conveys a broad pattern of expanded enslavement. That is, despite the British anti-slavery campaign, enslavement expanded across the Old World tropics until late in the nineteenth century in what is arguably a common pattern. ${ }^{21}$ This hypothesis provides one more argument that the effort of modeling population and migration on a large and systematic scale may bring about clarification of important patterns in large-scale social processes and relationships that had previously escaped notice.

\section{NOTES}

1 James E. Oeppen, "Life expectancy convergence among nations since 1820: separating the effects of technology and income," in T. Bengtsson (Ed.): Perspectives on mortality forecasting. III: the linear rise in life expectancy: history and prospects (Stockholm: Swedish Social Insurance Agency, 2006), 55-82.

2 Nathan Keyfitz, Applied Mathematical Demography, $3^{\text {rd }}$ ed. (New York: Springer, 2005); Patrick Manning "Slave Trade: The Formal Demography of a Global System." Social Science History 14 (1990):255-279.

${ }^{3}$ Ansley Coale and Paul Demeny, with Barbara Watkins, Regional Model Life Tables and Stable Populations, $2^{\text {nd }}$ ed. (New York: Academic Press, 1983).

${ }^{4}$ Ibid.

${ }^{5}$ In the example of African slave trade given below, these steps are accomplished by defining an out-migration schedule or "capture schedule" to initiate migration and a "partition" schedule to account for the direction of outmigrants.

${ }^{6}$ Manning, "Formal Demography."

${ }^{7}$ This approach was developed in detail in 2010. “African Population: Projections, 1851-1961.” Karl Ittmann, Dennis D. Cordell, and Gregory Maddox, eds., The Demographics of Empire: The Colonial Order and the Creation of Knowledge (Athens: Ohio University Press), pp. 245-275. For a critical view of this analysis, see Ewout Frankema and Morten Jerven, "Writing history backwards or sideways: towards a consensus on African population, 1850-2010,” Economic History Review 67 (2010):907-931.

${ }^{8}$ Manning, "Formal Demography.” 
${ }^{9}$ The Captive African population is measured three times: at the moment of its capture, as surviving captives complete their travels and exposure within sub-Saharan Africa (labeled as New Domestics and New Africa Exports), and as its survivors are disembarked at their destination (as New Abroad Exports) and added into the Export Slave population.

${ }^{10}$ The seventeen files include 2 for population, 6 for survival, 6 for fertility, 1 for capture, and 2 for partition. Most of the input files are 17x2 matrices (2 sexes, age groups); fertility schedules are 1x17 matrices (with zero values except for ages 14-19 through 45-49). They are posted online, along with a description of how they have been constructed. http://www.worldhistory.pitt.edu/Afropop.

${ }^{11}$ It will be possible for those running the simulation to set the number of runs for simulations in order to convey the impact of different social situations.

12 The difference is that the Partition schedule for the continental-enslavement version allows only for New Domestics and not for New Africa Exports; modeled rates of Capture can be adjusted up and down in attempt to match the historical rates of capture.

${ }^{13}$ The same demographic model, using data for European overseas migration by steamship in the nineteenth and twentieth centuries, yields quite a different set of values in its sensitivity analysis.

${ }^{14}$ The distinction is that rates of birth and death are taken here as parameters, since they do not vary during the course of a simulation run, while populations and migrant flows are taken as variables, since they vary during the course of a simulation. For the sensitivity analysis, we consider possible variation in all relevant variables and parameters.

${ }^{15}$ For purposes of the sensitivity analysis and in most simulation runs, the schedules of birth and mortality are assumed to be the same for Source and Captor populations and for Domestic and Export slave populations.

${ }^{16}$ Patrick Manning, "Impact of Slave Trade Exports on the Population of the Western Coast of Africa, 1700 1850,” in Serge Daget, ed., De la Traite a l'esclavage, 2 vols. (Paris, Société française d'histoire d'Outre-Mer), II:118-123. The three dependent variables were the same, but the independent variables combined survival and fertility into net rates of growth. The analysis was conducted with a much smaller number of runs, varying no more than two variables at a time. The simulation was based on one-year population groups rather than five-year groups; the input files were organized into slightly different variables. Nevertheless, the results showed that EXPRATIO was determined $82 \%$ by survival and fertility rates and $15 \%$ by the pattern of capture and partition ( ); GROWTH was determined $75 \%$ by the mortality and fertility rates in base populations and $15 \%$ by the pattern of capture and partition; and SEXRATIO among adults remaining on the African continent depended $42 \%$ on the pattern of capture and $32 \%$ on the partition of captives. The results of the new sensitivity analysis are thus shown to be quite robust.

${ }^{17}$ David Eltis et al., eds., Slave Voyages, http://www.slavevoyages.org.

${ }^{18}$ Martin A. Klein, Slavery and Colonial Rule in French West Africa (Cambridge: Cambridge University Press, 1998); Paul E. Lovejoy, Transformations in Slavery: A History of Slavery in Africa, $3^{\text {rd }}$ ed. (Cambridge: Cambridge University Press, 2011); Henri Médard and Shane Doyle, Slavery in the Great Lakes Region of East Africa (Oxford: James Currey); Gwyn Campbell, An Economic History of Imperial Madagascar: The rise and fall of an island empire (Cambridge: Cambridge University Press, 2004). 
19 Joseph E. Inikori, “Introduction,” in Inikori, ed., Forced Migration (London, 1982); Patrick Manning, Slavery and African Life: Occidental, Oriental, and African Slave Trades (Cambridge: Cambridge University Press, 1990); Paul E. Lovejoy, "The impact of the slave trade on Africa in the eighteenth and nineteenth centuries," Journal of African History 30 (1989).

${ }^{20}$ Did captives remain in their home region? If not, to which surrounding regions were they sent? At worst, estimation of migration in multiple directions, with varying rates of captive mortality, is complex. The simple solution adopted here is to assume that captives remained in the region of their capture, acknowledging that this will underestimate the level of captive mortality.

${ }^{21}$ Dale Tomich and Michael Zeuske, "The Second Slavery: Mass Slavery, World Economy, and Comparative Microhistories,” Review 31 (2008): 91-100; Bryce Beemer, "The Creole City in Southeast Asia: Slave Gathering Warfare and Culture Exchange in Burma, Thailand and Manipur, 1752-1885” (Ph.D. dissertation, University of Hawaii, 2013).

\section{REFERENCES}

Beemer, Bryce. "The Creole City in Southeast Asia: Slave Gathering Warfare and Culture Exchange in Burma, Thailand and Manipur, 1752-1885.” Ph.D. dissertation, University of Hawaii, 2013.

Campbell, Gwyn. An Economic History of Imperial Madagascar: The rise and fall of an island empire. Cambridge: Cambridge University Press, 2004.

Coale,Ansley, and Paul Demeny, with Barbara Watkins. Regional Model Life Tables and Stable Populations, $2^{\text {nd }}$ ed. New York: Academic Press, 1983.

Eltis, David, et al., eds., Slave Voyages, http://www.slavevoyages.org.

Frankema, Ewout, and Morten Jerven, "Writing history backwards or sideways: towards a consensus on African population, 1850-2010.” Economic History Review 67 (2010):907-931.

Inikori, Joseph E. “Introduction.” Inikori, ed., Forced Migration (London, 1982).

Keyfitz, Nathan. Applied Mathematical Demography, $3^{\text {rd }}$ ed. (New York: Springer, 2005.

Klein, Martin A. Slavery and Colonial Rule in French West Africa. Cambridge: Cambridge University Press, 1998.

Lovejoy, Paul E. “The impact of the slave trade on Africa in the eighteenth and nineteenth centuries," Journal of African History 30 (1989).

Lovejoy, Paul E. Transformations in Slavery: A History of Slavery in Africa, $3^{\text {rd }}$ ed. Cambridge: Cambridge University Press, 2011.

Manning, Patrick. "Slave Trade: The Formal Demography of a Global System." Social Science History 14 (1990):255-279. 
Manning, Patrick. “African Population: Projections, 1851-1961.” Karl Ittmann, Dennis D. Cordell, and Gregory Maddox, eds., The Demographics of Empire: The Colonial Order and the Creation of Knowledge (Athens: Ohio University Press), pp. 245-275.

Manning, Patrick. "Impact of Slave Trade Exports on the Population of the Western Coast of Africa, 1700 - 1850." Serge Daget, ed., De la Traite a l'esclavage, 2 vols. (Paris, Société française d'histoire d'Outre-Mer) II:118123.

Manning, Patrick. Slavery and African Life: Occidental, Oriental, and African Slave Trades. Cambridge: Cambridge University Press, 1990.

Médard, Henri, and Shane Doyle, Slavery in the Great Lakes Region of East Africa. Oxford: James Currey.

Oeppen, James E. "Life expectancy convergence among nations since 1820: separating the effects of technology and income." T. Bengtsson, ed., Perspectives on mortality forecasting. III: the linear rise in life expectancy: history and prospects (Stockholm: Swedish Social Insurance Agency, 2006), 55-82.

Tomich, Dale, and Michael Zeuske, "The Second Slavery: Mass Slavery, World Economy, and Comparative Microhistories,” Review 31 (2008): 91-100.

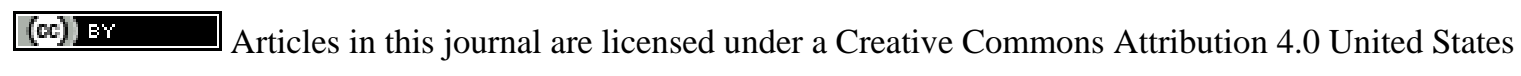

License.

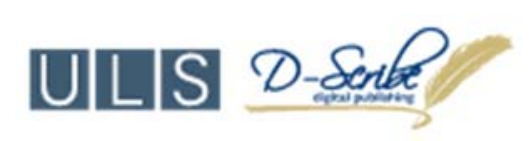

This journal is published by the University Library System of the University of Pittsburgh as part of its D-Scribe Digital Publishing Program and is cosponsored by the University of Pittsburgh Press. 